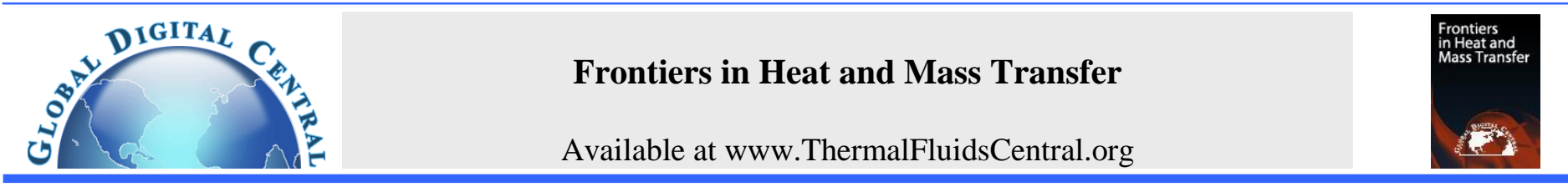

\title{
LAMINAR FORCED CONVECTION HEAT AND MASS TRANSFER IN A VENTURI TUBE WITH WETTED WALLS
}

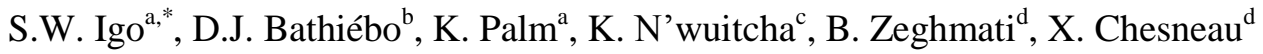 \\ ${ }^{a}$ Institut de Recherche en Sciences Appliquées et Technologies (IRSAT/CNRST). Département Energie. 03 BP 7047 Ouagadougou 03, Burkina Faso \\ ${ }^{b}$ Laboratoire d'Energie Thermique et Renouvelable (LETRE). Université de Ouagadougou, 03 BP 7021 Ouagadougou 03, Burkina Faso. \\ ${ }^{c}$ GPTE-LES, Département de physique. Université de Lomé. BP 1515, Togo. \\ ${ }^{d}$ Laboratoire de Mathématiques et Physique des Systèmes (LAMPS). 52 Avenue Paul Alduy 66860 Perpignan cedex 9, France.
}

\begin{abstract}
A combined heat and mass transfer in laminar forced convection flow in a rectangular venturi tube have been numerically simulated. A transformation has been used to transform the irregular profile of the venturi walls into a straight line. Transfers equations are solved using finite volume method, Gauss and Thomas algorithms. The influences of venturi effect, inlet Reynolds number and venturi diameter ratio on the heat and mass transfer are discussed in detail. Results presented as pressure gradient, Nusselt and Sherwood numbers profiles, velocity patterns and isotherms show that the throat play an important role on the heat an mass transfer in the venturi channel.
\end{abstract}

Keywords: Heat and mass transfer; laminar forced convection; evaporation; venturi tube.

\section{INTRODUCTION}

Venturi tubes are usually used for gas flow rate measurements. Their facility to design has led to many studies (Elperin et al., 2002; Jitschin et al., 1999; Jitschin, 2004; Li et al., 2000). They consist of a rectangular or circular channel with three parts: a convergent section, a throat and a divergent section or diffuser. Flow is accelerated in the convergent, reaches its maximum velocity in the throat and finally is decelerated in the diverging section. At the throat, a significant pressure drop occurs. Based on the inlet and outlet pressures, it is possible to calculate the gas flow using the well known Bernoulli's law. Thus, a venturi constitutes a converter which transforms physical quantity (gas flow), which is not easy to quantify, into one which is quite more conveniently to measure (pressure). If the hydrodynamic aspects are well known in venturi tubes, studies concerning thermal and mass transfer are scarce although these systems are more and more used in gas and oil industries for wet gas flow rate measurements (Lide et al., 2007). However, in others type of channels, heat and mass transfer between a wet wall and flow has been widely studied (Fujita, 1993; Baumann et al., 1986; Yan, 1993; Zheng et al., 1996). This process, widely encountered in practice, is used to protect walls from high temperature gas stream or to cool heated walls in industrials applications (evaporative cooling for waste heat disposal, towers cooling, turbine blade cooling, microelectronic system component cooling, etc.). Yan and Lin (1989) were the first to investigate the effects of liquid film evaporation from a wetted wall of a vertical channel on transfers. They showed that heat transfer is dominated by the latent heat. Later, Yan and Lin (1990) studied the effect of liquid film thickness evaporation in a vertical channel on transfers and conclude that it can be neglected when the liquid mass flow rate is small. Yan and Chyi (1995) studied the convective heat and mass transfer along an inclined heated plate with film evaporation. One of their results is about the Nusselt number which increases as the inclination angle increases due to the reduction of interfacial temperature. The Sherwood number is uninfluenced by the inclination angle, but is sensible to external flux and inlet velocity. The development of heat exchangers has motivated heat and mass transfer studies for wavy surfaces. Thus, the corrugated channels are widely used for heat enhancement in heat exchangers industries. Saniei and Dini (1993) studied, experimentally, heat transfer in wavy-wall channel and conclude that the maximum local Nusselt number was located upstream of the peak of each wave, while the minimum local Nusselt number was situated downstream, within a short distance of the peak of each wave. A numerical study of heat transfer through a channel with periodic array of wavy passages showed that in steady flow regime, the average Nusselt number for the wavy-wall channel is higher than those for a plane channel (Wang et al., 1995). For forced convection heat transfer in wavy-wall channel, the local Nusselt number and the local skin-friction coefficient harmonics have the same frequency as that of the wavy surface at smaller wavy amplitude-wave-length ratios or at low Reynolds number (Wang et al., 2002). In addition, the increases of Reynolds number leads to an increase of the local Nusselt number in the converging section, but do not influence significantly the local Nusselt number in the diverging section. 
As seen, although venturi tubes are used in hot moist gas flow rate measures, thermal and mass transfers studied about these devices have been neglected. Thus, the objective of this study is a numerical analysis of heat and mass transfer by forced convection through a venturi tube in which the walls are wetted.

\section{PROBLEM FORMULATION}

The venturi channel is formed by two isothermal plates of sections length L1, L2, L3, L4 and L5 (figure 1). The distance between the plates is $2 \mathrm{R}$ in the entrance region. Air with uniform temperature $\mathrm{T}_{\mathrm{o}}$ and relative humidity $\phi_{0}$ enters with uniform downward velocity $U_{0}$. The venturi wetted walls are submitted to the evaporation of water vapor. The thermophysical properties of air are depending on temperature and water vapor mass fraction. Their calculation can be found in the work of Feddaoui et al.,2003.

It is assumed that:

-The radial pressure gradient component is neglected,

-Dufour and Soret effects are neglected,

-Transfers are two-dimensional steady state and axisymmetric,

-The air is considered as an ideal gas.

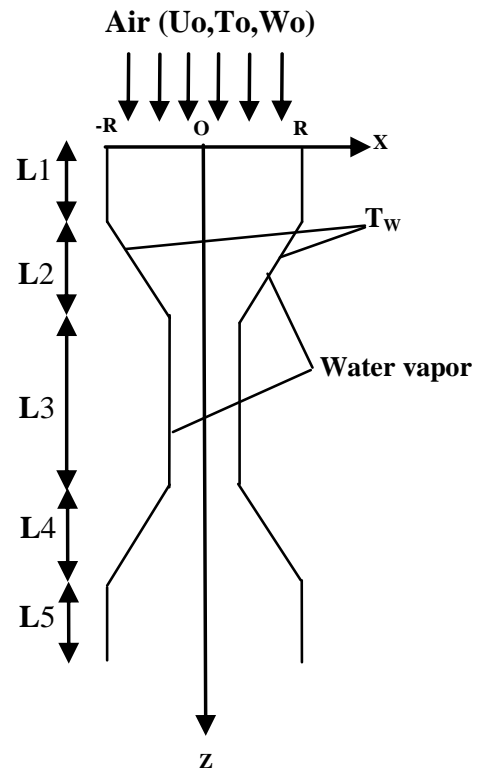

Fig. 1 Schematic representation of studied system in the $(\mathrm{o}, \mathrm{x}, \mathrm{z})$ referential

The dimensionless equations which govern the simultaneous heat and mass transfer by forced convection in the venturi are:

-Continuity equation

$\frac{\partial\left(\rho^{*} V^{*}\right)}{\partial x^{*}}+\frac{\partial\left(\rho^{*} U^{*}\right)}{\partial z^{*}}=0$

-Axial momentum equation

$\frac{\partial\left(\rho^{*} \mathrm{~V}^{*} \mathrm{U}^{*}\right)}{\partial \mathrm{x}^{*}}+\frac{\partial\left(\rho^{*} \mathrm{U}^{*} \mathrm{U}^{*}\right)}{\partial \mathrm{z}^{*}}=-\frac{\partial \mathrm{P}^{*}}{\partial \mathrm{z}^{*}}+$

$\frac{1}{\operatorname{Re}}\left[\frac{\partial}{\partial \mathrm{x}^{*}}\left(\mu^{*} \frac{\partial \mathrm{U}^{*}}{\partial \mathrm{x}^{*}}\right)+\frac{\partial}{\partial \mathrm{z}^{*}}\left(\mu^{*} \frac{\partial \mathrm{U}^{*}}{\partial \mathrm{z}^{*}}\right)\right]$
- Radial momentum equation

$\frac{\partial\left(\rho^{*} \mathrm{~V}^{*} \mathrm{~V}^{*}\right)}{\partial \mathrm{x}^{*}}+\frac{\partial\left(\rho^{*} \mathrm{U}^{*} \mathrm{~V}^{*}\right)}{\partial \mathrm{z}^{*}}=$

$\frac{1}{\operatorname{Re}}\left[\frac{\partial}{\partial \mathrm{x}^{*}}\left(\mu^{*} \frac{\partial \mathrm{V}^{*}}{\partial \mathrm{x}^{*}}\right)+\frac{\partial}{\partial \mathrm{z}^{*}}\left(\mu^{*} \frac{\partial \mathrm{V}^{*}}{\partial \mathrm{z}^{*}}\right)\right]$

-Energy equation

$$
\begin{aligned}
& \frac{\partial\left(\rho^{*} C_{\mathrm{p}}^{*} \mathrm{~V}^{*} \mathrm{~T}^{*}\right)}{\partial \mathrm{x}^{*}}+\frac{\partial\left(\rho^{*} \mathrm{C}_{\mathrm{p}}^{*} \mathrm{U}^{*} \mathrm{~T}^{*}\right)}{\partial \mathrm{z}^{*}}= \\
& \frac{1}{\operatorname{Re} \operatorname{Pr}}\left[\frac{\partial}{\partial \mathrm{x}^{*}}\left(\lambda^{*} \frac{\partial \mathrm{T}^{*}}{\partial \mathrm{x}^{*}}\right)+\frac{\partial}{\partial \mathrm{z}^{*}}\left(\lambda^{*} \frac{\partial \mathrm{T}^{*}}{\partial \mathrm{z}^{*}}\right)\right]
\end{aligned}
$$

- Water vapor diffusion equation

$$
\begin{aligned}
& \frac{\partial\left(\rho^{*} \mathrm{~V}^{*} \mathrm{~W}^{*}\right)}{\partial \mathrm{x}^{*}}+\frac{\partial\left(\rho^{*} \mathrm{U}^{*} \mathrm{~W}^{*}\right)}{\partial \mathrm{z}^{*}}= \\
& \frac{1}{\operatorname{Re} S c}\left[\frac{\partial}{\partial \mathrm{x}^{*}}\left(\mathrm{D}^{*} \frac{\partial \mathrm{W}^{*}}{\partial \mathrm{x}^{*}}\right)+\frac{\partial}{\partial z^{*}}\left(\mathrm{D}^{*} \frac{\partial \mathrm{W}^{*}}{\partial z^{*}}\right)\right]
\end{aligned}
$$

-Flow rate conservation

$$
\int \mathrm{U}^{*} \mathrm{dx}^{*}=\mathrm{Q}_{\mathrm{o}}{ }^{*}+\mathrm{Q}_{\mathrm{ev}}{ }^{*}
$$

$\mathrm{Q}_{\mathrm{o}}{ }^{*}$ and $\mathrm{Q}_{\mathrm{ev}}{ }^{*}$ are respectively the inlet gas flow rate and the cumulated evaporated flow rate.

\section{NUMERICAL PROCEDURE}

\subsection{Coordinates transformation}

In order to avoid the non-uniformity of the mesh spacing along the venturi plane, we transform the irregular profile of the walls into a straight line (figure 2):

$\left(\mathrm{x}^{*}, \mathrm{z}^{*}\right) \rightarrow(\eta, \xi)$ such as $\eta=\mathrm{x}^{*} / \mathrm{F}\left(\mathrm{z}^{*}\right)$ and $\xi=\mathrm{z}^{*}$ with $\mathrm{F}\left(\mathrm{z}^{*}\right)=\mathrm{az}+\mathrm{b}$, a and $\mathrm{b}$ are real number.
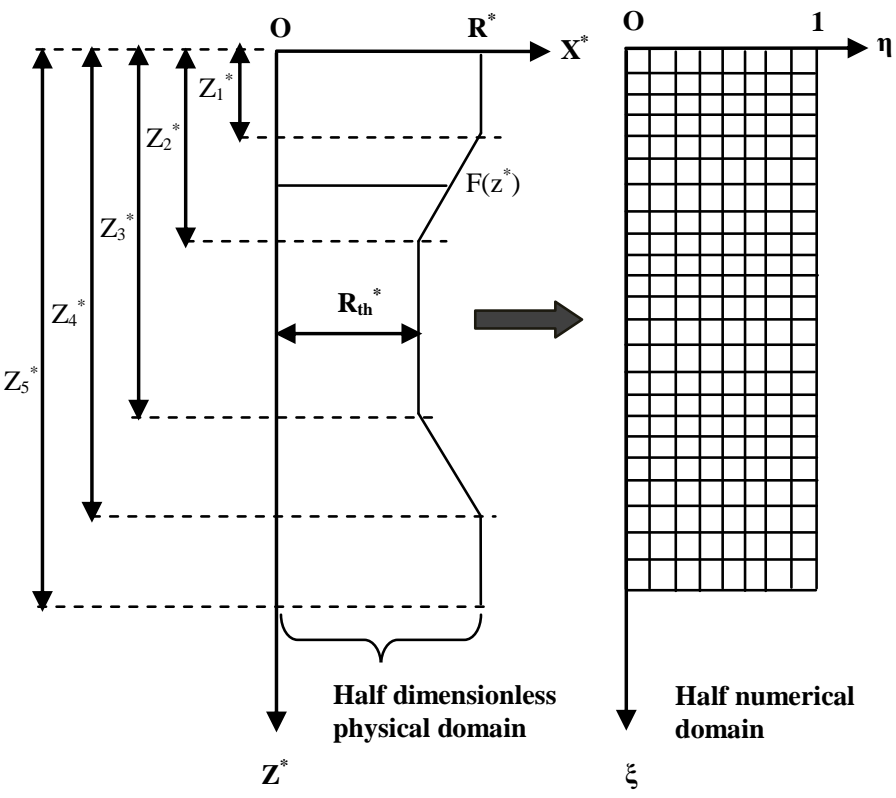

Fig. 2 Physical and numerical domain 
Real $\mathrm{a}$ and $\mathrm{b}$ are depending on $\mathrm{z}_{1}{ }^{*}, \mathrm{z}_{2}{ }^{*}, \mathrm{z}_{3}{ }^{*}, \mathrm{z}_{4}{ }^{*}, \mathrm{z}_{5}{ }^{*}, \mathrm{R}^{*}$ and $\mathrm{R}_{\mathrm{th}}{ }^{*}$ :

$0 \leq z^{*} \leq z_{1}^{*}: a=0, b=R^{*}$

$\mathrm{z}_{1}^{*} \leq \mathrm{z}^{*} \leq \mathrm{z}_{2}^{*}: a=\frac{\mathrm{R}_{\mathrm{th}}{ }^{*}-\mathrm{R}^{*}}{\mathrm{z}_{2}{ }^{*}-z_{1}{ }^{*}}, b=\frac{\mathrm{z}_{2}{ }^{*} \mathrm{R}^{*}-\mathrm{z}_{1}{ }^{*} \mathrm{R}_{\mathrm{th}}{ }^{*}}{\mathrm{z}_{2}{ }^{*}-\mathrm{z}_{1}{ }^{*}}$

$\mathrm{z}_{2}{ }^{*} \leq \mathrm{z}^{*} \leq \mathrm{z}_{3}{ }^{*}: \mathrm{a}=0, \mathrm{~b}=\mathrm{R}_{\mathrm{th}}{ }^{*}$

$\mathrm{z}_{3}{ }^{*} \leq \mathrm{z}^{*} \leq \mathrm{z}_{4}{ }^{*}: a=\frac{\mathrm{R}^{*}-\mathrm{R}_{\mathrm{th}}{ }^{*}}{\mathrm{z}_{4}{ }^{*}-\mathrm{z}_{3}{ }^{*}}, b=\frac{\mathrm{z}_{4}{ }^{*} \mathrm{R}_{\mathrm{th}}{ }^{*}-\mathrm{z}_{3}{ }^{*} \mathrm{R}^{*}}{\mathrm{z}_{4}{ }^{*}-\mathrm{z}_{3}{ }^{*}}$

$\mathrm{z}_{4}{ }^{*} \leq \mathrm{z}^{*} \leq \mathrm{z}_{5}{ }^{*}: \mathrm{a}=0, \mathrm{~b}=\mathrm{R}^{*}$

The radial and axial derivatives in the physical domain are expressed in the numerical one:

$$
\begin{aligned}
& \frac{\partial}{\partial \mathrm{x}}=\frac{\partial}{\partial \eta} \frac{\partial \eta}{\partial \mathrm{x}}+\frac{\partial}{\partial \xi} \frac{\partial \xi}{\partial \mathrm{x}}=\frac{1}{\mathrm{a} \xi+\mathrm{b}} \frac{\partial}{\partial \eta} \\
& \frac{\partial}{\partial \mathrm{z}}=\frac{\partial}{\partial \eta} \frac{\partial \eta}{\partial \mathrm{z}}+\frac{\partial}{\partial \xi} \frac{\partial \xi}{\partial \mathrm{z}}=\frac{\partial}{\partial \xi}-\left(\frac{\mathrm{a} \eta}{\mathrm{a} \xi+\mathrm{b}}\right) \frac{\partial}{\partial \eta}
\end{aligned}
$$

In the new coordinate system $(\eta, \xi)$, the equations $2-5$ are:

$$
\begin{aligned}
& \frac{1}{\mathrm{a} \xi+\mathrm{b}} \frac{\partial\left(\alpha \mathrm{V}^{*} \Phi\right)}{\partial \eta}+\frac{\partial\left(\alpha \mathrm{U}^{*} \Phi\right)}{\partial \xi}-\left(\frac{\mathrm{a} \eta}{\mathrm{a} \xi+\mathrm{b}}\right) \frac{\partial\left(\alpha \mathrm{U}^{*} \Phi\right)}{\partial \eta}=\mathrm{B} \\
& +\kappa\left[\frac{1}{\mathrm{a} \xi+\mathrm{b}} \frac{\partial}{\partial \eta}\left(\frac{\chi}{\mathrm{a} \xi+\mathrm{b}} \frac{\partial \Phi}{\partial \eta}\right)\right]+ \\
& \kappa\left[\left(\frac{\partial}{\partial \xi}-\left(\frac{\mathrm{a} \eta}{\mathrm{a} \xi+\mathrm{b}}\right) \frac{\partial}{\partial \eta}\right) \chi\left(\frac{\partial \Phi}{\partial \xi}-\left(\frac{\mathrm{a} \eta}{\mathrm{a} \xi+\mathrm{b}}\right) \frac{\partial \Phi}{\partial \eta}\right)\right]
\end{aligned}
$$

where $\alpha, \mathrm{B}, \kappa$, and $\chi$ are defined in table 1 :

Table1: Expression of coefficients $\alpha, \mathrm{B}, \kappa$, and $\chi$

\begin{tabular}{|l|l|l|l|l|}
\hline$\Phi$ & $\alpha$ & $B$ & $\kappa$ & $\chi$ \\
\hline $\mathrm{U}^{*}$ & $\rho^{*}$ & $-\partial \mathrm{P}^{*} / \partial \xi$ & $1 / \operatorname{Re}$ & $\mu^{*}$ \\
\hline $\mathrm{V}^{*}$ & $\rho^{*}$ & 0 & $1 / \operatorname{Re}$ & $\mu^{*}$ \\
\hline $\mathrm{T}^{*}$ & $\rho^{*} \mathrm{C}_{\mathrm{p}}{ }^{*}$ & 0 & $1 / \operatorname{RePr}$ & $\lambda^{*}$ \\
\hline $\mathrm{W}^{*}$ & $\rho^{*}$ & 0 & $1 / \operatorname{ReSc}$ & $\mathrm{D}^{*}$ \\
\hline
\end{tabular}

Equation (1) and (6) are, respectively:

$$
\begin{aligned}
& \frac{1}{a \xi+b} \frac{\partial\left(\rho^{*} V^{*}\right)}{\partial \eta}+\frac{\partial\left(\rho^{*} U^{*}\right)}{\partial \xi}-\left(\frac{a \eta}{a \xi+b}\right) \frac{\partial\left(\rho^{*} U^{*}\right)}{\partial \eta}=0 \\
& \int U^{*}(a \xi+b) d \eta=Q_{o}^{*}+Q_{e v}^{*}
\end{aligned}
$$

\subsection{Boundaries conditions}

-At the inlet $(\xi=0,0 \leq \eta \leq 1)$

$$
U^{*}(\eta, \xi)=\frac{3}{2}\left(1-\eta^{2}\right) ; V^{*}(\eta, \xi)=0 ; T^{*}(\eta, \xi)=1 ; W^{*}(\eta, \xi)=1
$$

-At the outlet $\left(\xi=\mathrm{L} / \mathrm{D}_{\mathrm{h}}, 0 \leq \eta \leq 1\right)$ $\frac{\partial \mathrm{U}^{*}(\eta, \xi)}{\partial \xi}=0 ; \frac{\partial \mathrm{V}^{*}(\eta, \xi)}{\partial \xi}=0 ; \frac{\partial \mathrm{T}^{*}(\eta, \xi)}{\partial \xi}=0 ; \frac{\partial \mathrm{W}^{*}(\eta, \xi)}{\partial \xi}=0$

-At the wall $\left(0 \leq \xi \leq \mathrm{L} / \mathrm{D}_{\mathrm{h}}, \eta=1\right)$

$\mathrm{U}^{*}(\eta, \xi)=0 ; \mathrm{T}^{*}(\eta, \xi)=\mathrm{T}_{\mathrm{w}} / \mathrm{T}_{\mathrm{o}} ; \mathrm{W}^{*}(\eta, \xi)=\mathrm{W}_{\mathrm{w}} / \mathrm{W}_{\mathrm{o}} ; \mathrm{V}^{*}(\eta, \xi)=\mathrm{V}_{\mathrm{ev}}^{*}$

-At the axis of symmetry $\left(0 \leq \xi \leq L / D_{h}, \eta=0\right)$

$\frac{\partial \mathrm{U}^{*}(\eta, \xi)}{\partial \eta}=0 ; \mathrm{V}^{*}(\eta, \xi)=0 ; \frac{\partial \mathrm{T}^{*}(\eta, \xi)}{\partial \eta}=0 ; \frac{\partial \mathrm{W}^{*}(\eta, \xi)}{\partial \eta}=0$

The dimensionless evaporating velocity at the wetted wall can be evaluated using the following relation (Eckert et Frake Jr, 1972):

$$
\mathrm{V}_{\text {ev }}^{*}=-\left.\frac{\mathrm{D}}{\mathrm{UoD}_{\mathrm{h}}\left(1 / \mathrm{W}_{\mathrm{o}}-\mathrm{W}_{\mathrm{w}}^{*}\right)} \frac{1}{\mathrm{~F}(\xi)} \frac{\partial \mathrm{W}^{*}}{\partial \eta}\right|_{\mathrm{w}}
$$

According to Dalton's law, the mass fraction of water vapor at the wall corresponds to saturation conditions at $\mathrm{T}_{\mathrm{w}}$ :

$$
\mathrm{W}_{\mathrm{w}}=\mathrm{P}_{\mathrm{w}} \mathrm{M}_{\mathrm{v}} /\left[\mathrm{P}_{\mathrm{w}} \mathrm{M}_{\mathrm{v}}+\left(\mathrm{P}-\mathrm{P}_{\mathrm{w}}\right) \cdot \mathrm{M}_{\mathrm{a}}\right]
$$

The heat flux between the wet walls and the flow is equal to the sum of the latent and the sensible heat:

$\mathrm{q}_{\mathrm{T}}=\mathrm{q}_{\mathrm{S}}+\mathrm{q}_{\mathrm{L}}=\left.\lambda \frac{\partial \mathrm{T}}{\partial \mathrm{x}}\right|_{\mathrm{w}}+\dot{\mathrm{m}}_{\mathrm{w}}^{\prime \prime} \mathrm{h}_{\mathrm{fg}}$

$\dot{\mathrm{m}}_{\mathrm{w}}{ }_{\mathrm{w}}$ and $\mathrm{h}_{\mathrm{fg}}$ are, respectively, the evaporated mass flux and the latent heat of vaporization:

$\dot{\mathrm{m}}_{\mathrm{w}}^{\prime \prime}=\rho \mathrm{V}_{\mathrm{ev}}$

We characterize heat transfer by the total Nusselt number $\mathrm{Nu}_{\mathrm{T}}$ :

$\mathrm{Nu}_{\mathrm{T}}=\frac{\mathrm{hD}_{\mathrm{h}}}{\lambda}=\frac{\mathrm{q}_{\mathrm{T}} \mathrm{D}_{\mathrm{h}}}{\lambda\left(\mathrm{T}_{\mathrm{w}}-\mathrm{T}_{\mathrm{b}}\right)}=\mathrm{Nu}_{\mathrm{s}}+\mathrm{Nu}_{\mathrm{L}}$

$\mathrm{Nu}_{\mathrm{s}}$ is the sensible Nusselt number and $\mathrm{Nu}_{\mathrm{L}}$ the latent Nusselt number:

$$
\begin{aligned}
& \mathrm{Nu}_{\mathrm{s}}=\left.\frac{1}{\left(\mathrm{~T}_{\mathrm{w}}^{*}-\mathrm{T}_{\mathrm{b}}^{*}\right)} \frac{1}{\mathrm{~F}(\xi)} \frac{\partial \mathrm{T}^{*}}{\partial \eta}\right|_{\mathrm{W}} \\
& \mathrm{Nu}_{\mathrm{L}}=\frac{\dot{\mathrm{m}}_{\mathrm{w}} \mathrm{h}_{\mathrm{fg}} \mathrm{D}_{\mathrm{h}}}{\lambda \mathrm{T}_{\mathrm{O}}\left(\mathrm{T}_{\mathrm{w}}^{*}-\mathrm{T}_{\mathrm{b}}^{*}\right)}
\end{aligned}
$$

Similarly, the Sherwood number is defined by:

$$
\mathrm{Sh}=\frac{\mathrm{h}_{\mathrm{M}} \mathrm{D}_{\mathrm{h}}}{\mathrm{D}}=\left.\frac{1}{\left(\mathrm{~W}_{\mathrm{W}}^{*}-\mathrm{W}_{\mathrm{b}}^{*}\right)} \frac{1}{\mathrm{~F}(\xi)} \frac{\partial \mathrm{W}^{*}}{\partial \eta}\right|_{\mathrm{W}}
$$

The equations (9) associated to boundaries conditions (12-15) are discretized using an implicite scheme based on the finite volume method. The system of algebraic equation deduced from discretisation of the radial momentum equation component, energy and diffusion equations, is for each equation tri-diagonal; so it was solved by Thomas algorithm. The discretisation of axial momentum equation leads to an algebraic equation system composed of $\mathrm{M}$ equations and $(\mathrm{M}+1)$ unknowns variables (U and P). Consequently, it was solved with Gauss algorithm.

The convergence was obtained when the following criterion was satisfied: 
$\frac{\Phi_{i, j}^{n+1}-\Phi_{i, j}^{n}}{\Phi_{i, j}^{n+1}}<10^{-5}, \Phi=U^{*}, V^{*}, T^{*}, W^{*}$

where the superscript $\mathrm{n}$ designates the iteration number.

The validation of our numerical code has been carried out by comparing our results with the most closely numerical solution (Yan and Lin, 1988).

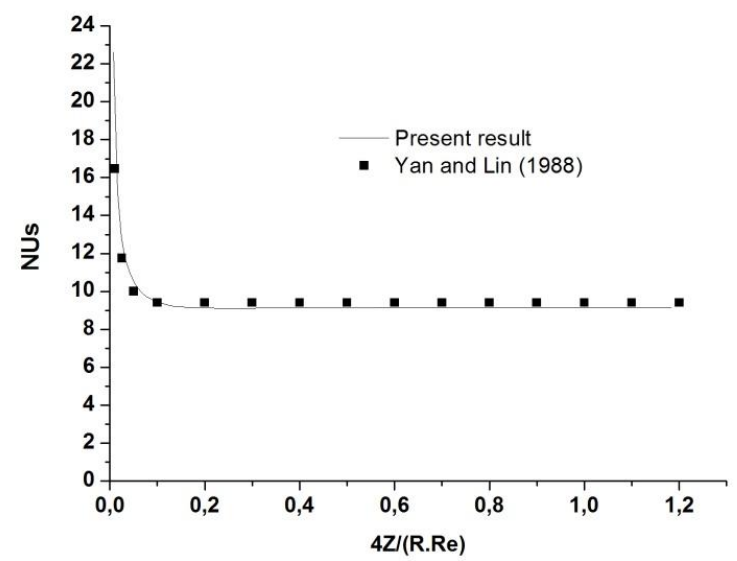

Fig. 3 Profile of calculated Nusselt number $\left(\mathrm{T}_{0}=20^{\circ} \mathrm{C}, \mathrm{T}_{\mathrm{w}}=40^{\circ} \mathrm{C}\right.$, $\left.\phi_{\mathrm{o}}=50 \%, \operatorname{Pr}=0.703, \mathrm{Sc}=0.592, \operatorname{Re}=500\right)$

As seen in figure 3, the discrepancies between our results and those of Yan and Lin do not exceed $0.01 \%$.

The computational grid is uniform in the two directions. The step length in each direction is chosen by numerical experiments provided by the stabilities conditions of Thomas and Gauss algorithms. To ensure that the results are grid independent, computations are carried out for several mesh size. The effect of the grid size on the Nusselt number leads to a mesh size of 60 nodes in the $\eta$ direction and 120 nodes in the $\xi$ direction corresponding to the step lengths $(\Delta \eta, \Delta \xi) . \Delta \eta=17.10^{-3} ; \Delta \xi=$ $38.10^{-3}$. As seen, an increase of the number of nodes by a factor of four does not influence the results significantly. The discrepancies between Nusselt values for mesh size $(60 * 120)$ and mesh size $(120 * 240)$ reported in table 2 is less than $5 \%$.

Table 2: Grid independence

\begin{tabular}{l|l|l|l|l} 
Grid $(\eta * \xi)$ & $\xi=0.2$ & $\xi=0.4$ & $\xi=0.6$ & $\xi=0.8$ \\
\hline \multicolumn{5}{c}{ Values of $\mathrm{Nu}_{\mathrm{s}}(\mathrm{Re}=500)$} \\
\hline$(60 * 120)$ & 15.80713 & 23.96526 & 9.24108 & 6.23658 \\
\hline$(120 * 240)$ & 15.92985 & 24.06678 & 9.45009 & 6.46739
\end{tabular}

The validation of our numerical code is presented for $\mathrm{Re}=500$ as results reported by Yan and Lin. However, for the three Reynolds number used in ours computations, we ensure that results are grid independent. For $\mathrm{Re}=500$ we obtained a grid independent solution for a spatial grid $60 * 120$. Whereas a spatial grid refinement for the others Reynolds numbers $(1000,1500)$ doesn't contribute to ameliorate the precision of the solution. Consequently, we have retained the spatial grid $60 * 120$.

\section{RESULTS AND DISCUSSION}

Calculations were performed for $\mathrm{L} 1=0.1 \mathrm{~m}, \mathrm{~L} 2=0.2 \mathrm{~m}, \mathrm{~L} 3=0.15 \mathrm{~m}$, $\mathrm{L} 4=0.3 \mathrm{~m}, \mathrm{~L} 5=0.15 \mathrm{~m}, \mathrm{R}=0.1 \mathrm{~m}, \mathrm{~T}_{\mathrm{o}}=293.15 \mathrm{~K}, \mathrm{~T}_{\mathrm{w}}=298.5 \mathrm{~K}$ and $\mathrm{a}$ venturi diameter ratio $\beta$ in the range of 0.25 to 1 .

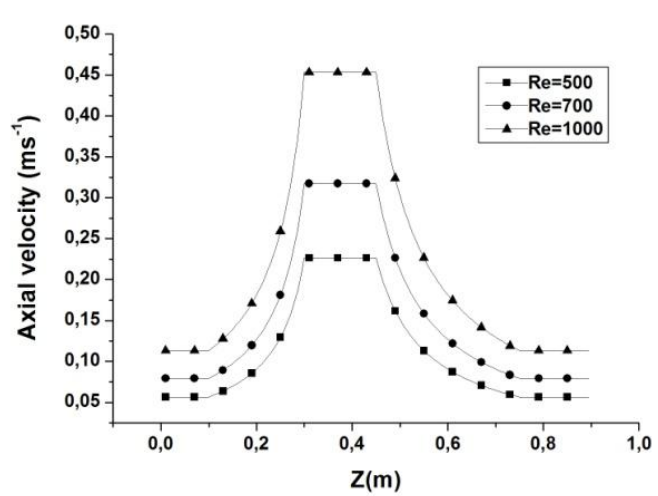

Fig. 4 Axial velocity versus Reynolds number. $\beta=0.25$

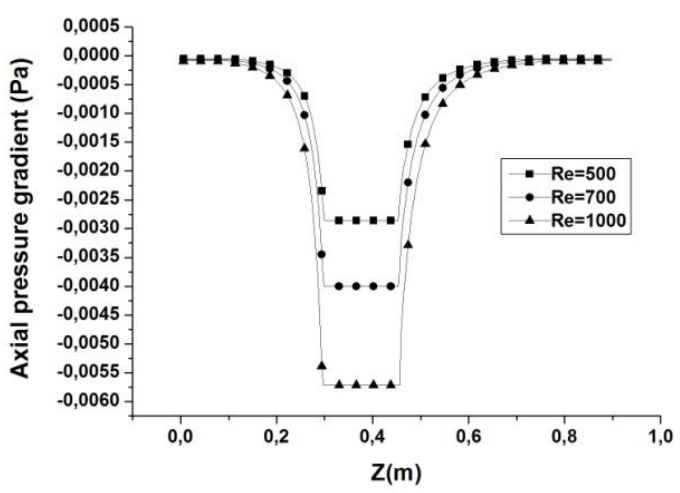

Fig. 5 Axial pressure gradient versus Reynolds number. $\beta=0.25$

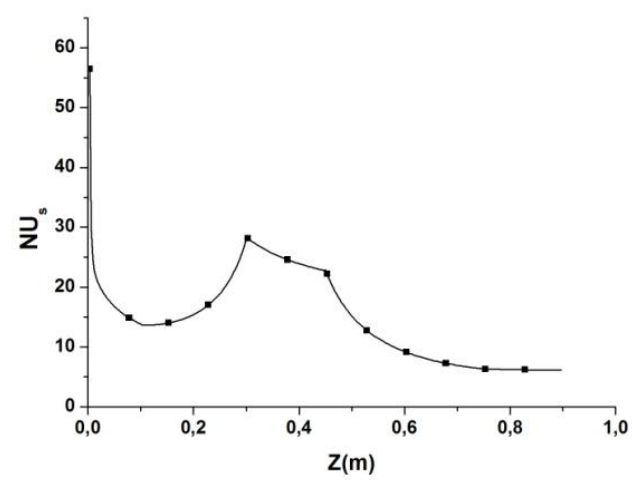

Fig. 6 Sensible Nusselt number evolution along the venturi: $\operatorname{Re}=500$. $\beta=0.25$

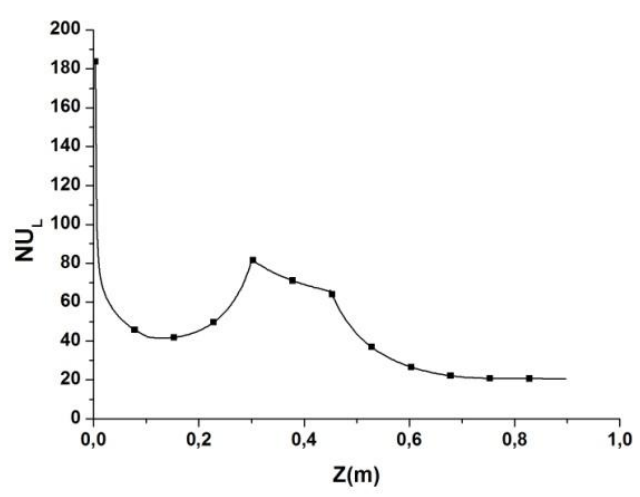

Fig. 7 Latent Nusselt number evolution along the venturi: $\mathrm{Re}=500$. $\beta=0.25$ 


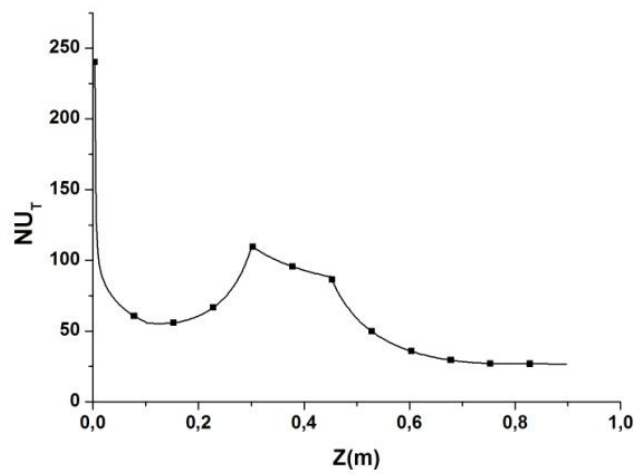

Fig. 8 Total Nusselt number evolution along the venturi: $\mathrm{Re}=500$. $\beta=0.25$

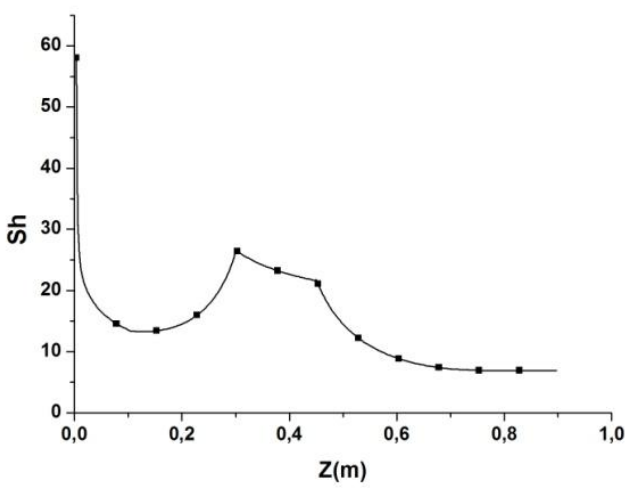

Fig. 9 Sherwood number evolution along the venturi: $R e=500 . \beta=0.25$

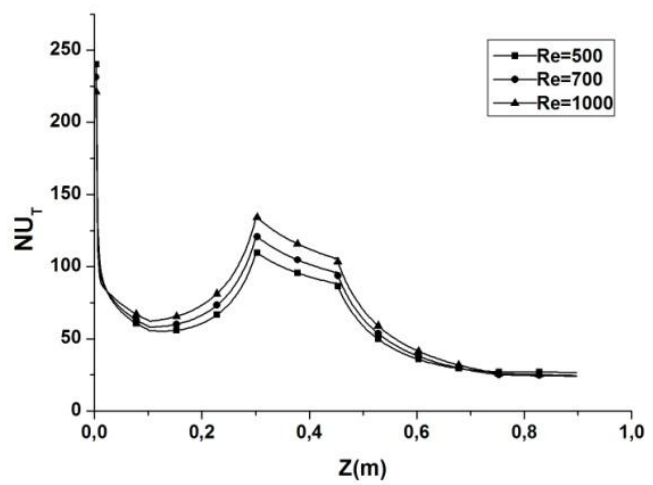

Fig. 10 Total Nusselt number versus Reynolds number. $\beta=0.25$

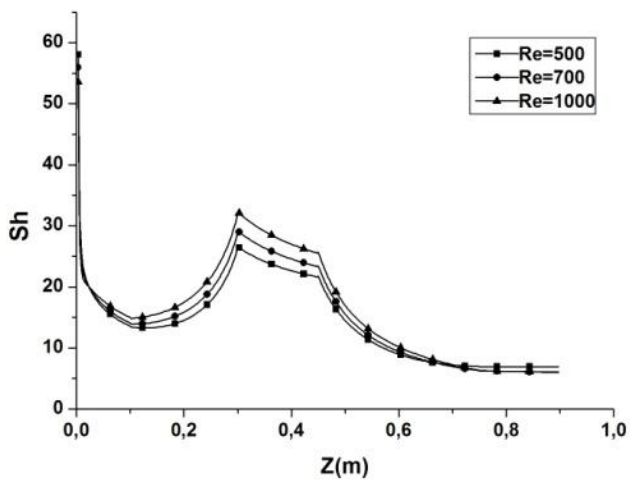

Fig. 11 Sherwood number versus Reynolds number. $\beta=0.25$

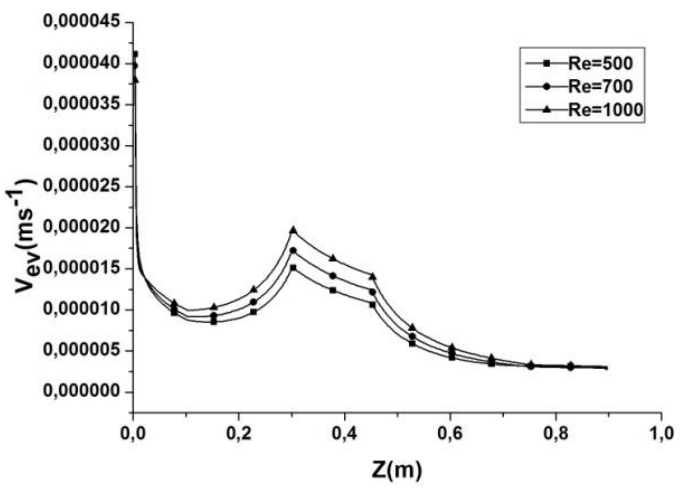

Fig. 12 Evaporation velocity at the venturi wall, versus Reynolds number. $\beta=0.25$

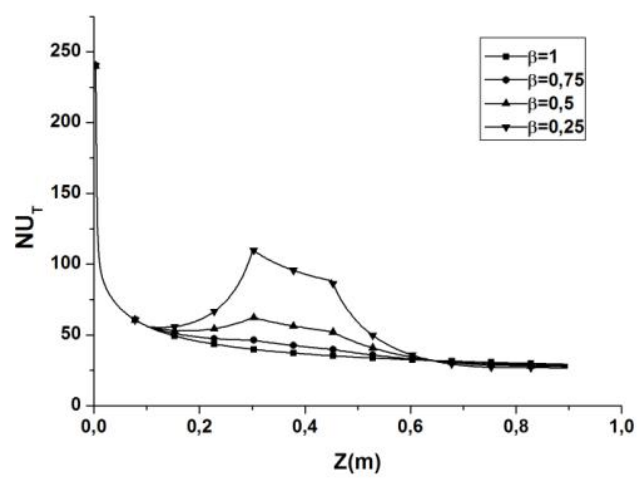

Fig. 13 Total Nusselt number versus venturi diameter ratio. $\mathrm{Re}=500$

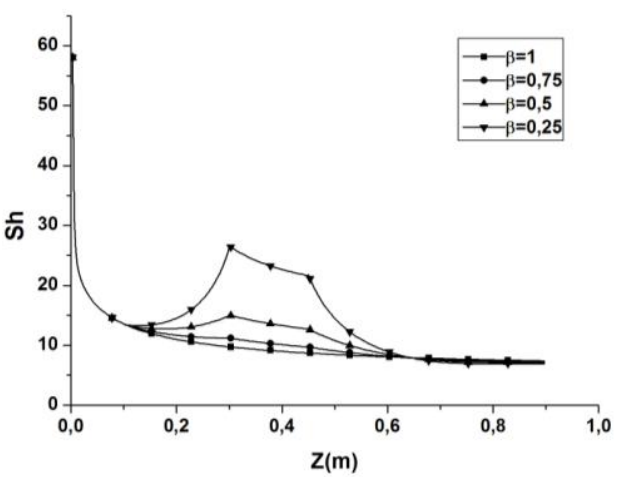

Fig. 14 Sherwood number versus venturi diameter ratio. $\mathrm{Re}=500$

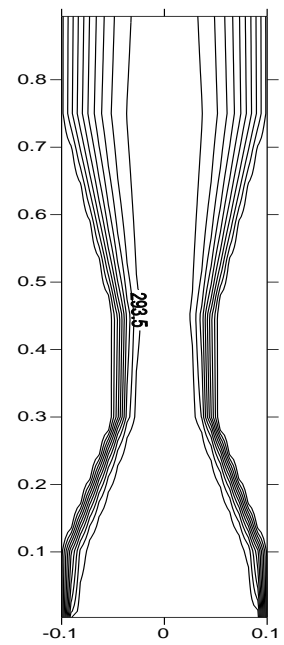

Fig. 15 Isotherms: $\operatorname{Re}=500 . \beta=0.25$

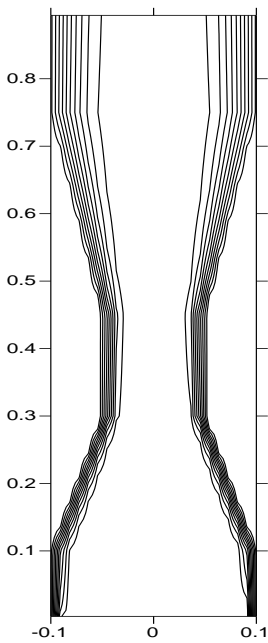

Fig. 16 Isotherms: $\mathrm{Re}=1000 . \beta=0.25$

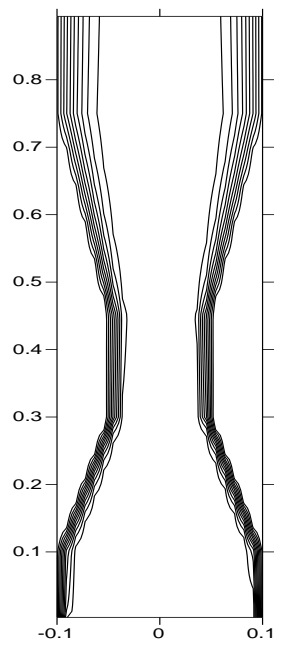

Fig. 17 Isotherms: $\mathrm{Re}=1500 . \beta=0.25$ 
Figures 4-5 illustrate the effect of Reynolds number on the velocity and the axial pressure evolution in the venturi. In the converging section, there is a continuous increase of the pressure drop due to the acceleration of the flow resulting of the conversion of the potential energy into kinetic one (venturi effect). Maximum velocity of the flow is reached in the throat. In addition, the increasing of Reynolds number increase venturi effect.

Nusselt and Sherwood numbers for a fixed Reynolds number are presented in figures 6-9. Venturi effect on heat and mass transfers is observed; both heat and mass transfer increase in the convergent section due to the increasing of the flow velocity which increases convective transfers. The decreasing of heat and mass transfer is observed in the throat because the velocity becomes constant. This decreasing seems to be linear. In the diverging section, the velocity decreases as the channel cross section increases, consequently convective transfers decrease in this venturi part as in a wall plane channel. We observed that the heat transfer is dominated by the latent heat in the all venturi tube. This result is an agreement with Yan et al. (1989) one for a wall plane channel transfers. The sensible Nusselt number is similar to the Sherwood number because the Prandtl number is approximately equal to the Schmidt number $(\mathrm{Pr}=0.71, \mathrm{Sc}=0.69)$.

Figures 10-12 illustrate the effect of the inlet Reynolds number on heat and mass transfers. The augmentation of heat and mass transfers as the Reynolds number increase is due to the increase of convective and conductive transfers and the convective transfer is dominant. This increase is more important through the throat than in the convergent section, and more important in the convergent than the divergent. The evaporation velocity profile at the venturi wall is the consequence of the increasing of mass transfer.

In figures 13-14, we present the effect of venturi diameter ratio on heat and mass transfer. $\beta$ equal to 1 is a particular case for wall plane channel. When $\beta$ decreases transfers increases because channel is progressively transformed to a venturi channel, and the flow and transfers are depending of venturi effect. The venturi transformation effect is more sensible in the throat than the others sections of the venturi.

Isotherms versus Reynolds number are presented in figures 15-17. Isotherms spread along the venturi wall; this structure means that transfers in the wall vicinity are assumed by conduction mode. In the convergent section and in the throat, we observe a tightening of isotherms along the wall and a margin of isotherms along the mean flow. The tightening along walls increases as the Reynolds number increases, because of the decrease of conductive effects.

\section{CONCLUSIONS}

Heat and mass transfer with evaporation at the venturi wet wall channel have been numerically studied. The venturi effect, the inlet Reynolds number and the venturi diameter ratio on heat and mass transfers are been investigated in details. The main results are summarized as follows:

- Heat and mass transfers increase in the converging section, decreases almost linearly in the throat and are similar to a wall plane channel heat and mass transfers in the diverging section. In the all venturi sections, the heat transfer is dominated by the latent heat.

- Heat and mass transfers, and the evaporation velocity increase as the Reynolds number increases. This augmentation is more important in the throat than the others sections of the venturi.

- Heat and mass transfers increase as the venturi diameter ratio decreases. This increase is also more important in the throat than the others sections of the venturi.

\section{NOMENCLATURE}

$C_{p^{*}}{ }^{*} \quad$ dimensionless specific heat,$=\mathrm{C}_{\mathrm{p}} / \mathrm{C}_{\mathrm{po}}$

$D^{*} \quad$ dimensionless mass diffusion coefficient, $=\mathrm{D} / \mathrm{D}_{\mathrm{o}}$

$D_{h} \quad$ hydraulic diameter $(\mathrm{m}),=2 \mathrm{R}$

$h \quad$ convective heat transfer coefficient $\left(\mathrm{Wm}^{-2} \mathrm{~K}^{-1}\right)$

$h_{M} \quad$ mass transfer coefficient $\left(\mathrm{ms}^{-1}\right)$

$h_{f g} \quad$ latent heat of vaporization $\left(\mathrm{Jkg}^{-1}\right)$

$M \quad$ molar mass $\left(\mathrm{kgmol}^{-1}\right)$

$N U_{L} \quad$ latent Nusselt number

$N U_{S} \quad$ sensible Nusselt number

$N U_{T} \quad$ total Nusselt number

$P^{*} \quad$ dimensionless pressure of air, $=\mathrm{P} / \mathrm{P}_{\mathrm{o}}$

$\operatorname{Pr} \quad$ Prandtl number,$=\mu_{\mathrm{o}} \mathrm{C}_{\mathrm{po}} / \lambda_{\mathrm{o}}$

$Q^{*} \quad$ dimensionless flow rate, $=\mathrm{Q} / \mathrm{Q}_{0}$

$R \quad$ inlet radius

Re Reynolds number, $=\rho_{\mathrm{o}} \mathrm{UoD}_{\mathrm{h}} / \mu_{\mathrm{o}}$

Sc $\quad$ Schmidt number,$=\mu_{0} / \rho_{0} D_{0}$

Sh Sherwood number

$T^{*} \quad$ dimensionless temperature, $=\mathrm{T} / \mathrm{T}_{\mathrm{o}}$

$U^{*} \quad$ dimensionless axial velocity component, $=\mathrm{U} / \mathrm{U}_{\mathrm{o}}$

$V^{*} \quad$ dimensionless radial velocity component $=\mathrm{V} / \mathrm{U}_{\mathrm{o}}$

$W^{*} \quad$ dimensionless water vapor mass fraction,$=\mathrm{W} / \mathrm{W}_{\mathrm{o}}$

$X^{*} \quad$ dimensionless radial coordinate, $=\mathrm{X} / \mathrm{D}_{\mathrm{h}}$

$Z^{*} \quad$ dimensionless axial coordinate,$=Z / D_{h}$

Greek Symbols

$\beta \quad$ venturi diameter ratio $=$ throat diameter $/ 2 \mathrm{R}$

$\rho^{*} \quad$ dimensionless air density, $=\rho / \rho_{\mathrm{o}}$

$\mu^{*} \quad$ dimensionless air viscosity, $=\mu / \mu_{0}$

$\phi \quad$ air relative humidity

$\eta \quad$ numerical radial coordinate

$\xi \quad$ numerical axial coordinate

$\begin{array}{ll}\text { Subscripts } \\ a & \text { air } \\ b & \text { bulk quantity } \\ e v & \text { evaporation } \\ o & \text { inlet } \\ t h & \text { throat } \\ v & \text { vapor } \\ w & \text { wall }\end{array}$

\section{REFERENCES}

Baumann W. M., and Thiele, F., 1986, "Heat and mass transfer in twocomponent film evaporation in a vertical tube," Proc.8th Int. Heat Transfer, San Francisco, 4, 1843-1846.

Eckert, E. R. G., Frake Jr, R. M., 1972, "Analysis of Heat and Mass transfer," McGraw-Hill, New York.

Elperin, T., Fominykh, A., Klochko, M., 2002, "Performance of a Venturi meter in gas-liquid flow in the presence of dissolved gases," Flow Measurement and Instrumentation, 13, 13-16. http://dx.doi.org/10.1016/S0955-5986(02)00013-4.

Feddaoui, M., Mir, A., Belahmidi, E.,2003, "Cocurrent turbulent mixed convection heat and mass transfer in falling film of water inside a vertical heated tube," Int J.Heat Mass transfer, 46, 3497-3509. http://dx.doi.org/10.1016/S0017-9310(03)00129-7.

Fujita, T., 1993, "Falling film in absorption machines," Int.J. Refrig.16, 282-294.

http://dx.doi.org/10.1016/0140-7007(93)90081-I. 
Jitschin, W., Ronzheimer, M., Khodabakhshi, S., 1999, "Gas flow measurement by means of orifices and venturi tubes," Vacuum, 53, 181185.

http://dx.doi.org/10.1016/S0042-207X(98)00352-2.

Jitschin, W., 2004, "Gas flow measurement by the thin orifice and the classical venturi tube," Vacuum, 76, 89-100.

http://dx.doi.org/10.1016/j.vacuum.2004.05.014.

Li, X., Lee, W. Y., Wong, Zohar, M.Y., 2000, "Gas flow in constriction microdevices," Sensors and Actuators, 83, 277-283.

http://dx.doi.org/10.1016/S0924-4247(99)00308-8.

Lide, F., Tao ,Z., Ningde, J., 2007, “A comparison of correlations used for venturi wet gas metering in oil and gas industry," Journal of Petroleum Science and Engineering, 57, 247-256.

http://dx.doi.org/10.1016/j.petrol.2006.10.010.

Saniei, N., Dini, S., 1993, "Heat transfer characteristics in a wavywalled channel," ASME J. Heat Transfer, 115, 788-792.

http://dx.doi.org/10.1115/1.2910756.

Wang, C.-C., Chen, C.-K., 2002, "Forced convection in wavy channel," Int J. Heat Mass transfer, 45, 2587-2595. http://dx.doi.org/10.1016/S0017-9310(01)00335-0.

Wang, G., Vanka, S. P., 1995, "Convective heat transfer in wavy passage," Int. J. Heat Mass Transfer, 38, 3219-3230.

http://dx.doi.org/10.1016/0017-9310(95)00051-A.
Yan, W. M., 1993, "Mixed convection heat transfer in a vertical channel with film evaporation," Canad.J.Chem. Eng, 71, 54-61.

http://dx.doi.org/10.1002/cjce.5450710108.

Yan, W. M., Lin, T.F., 1989, "Effects of laminar mixed convection in a vertical channel," J.Thermphys, 3, 94-94.

http://dx.doi.org/10.2514/3.56231.

Yan, W. M., and Lin, T.F., 1990, "Combined heat and mass transfer in natural convection between vertical plates with film evaporation," Int J.Heat Mass transfer, 33, 529-541.

http://dx.doi.org/10.1016/0017-9310(90)90187-Y.

Yan, W. M., Soong, C. Y., 1995, "Combined heat and mass transfer along an inclined heated plate with film evaporation," Int J.Heat Mass transfer, 38, 1261-1269.

http://dx.doi.org/10.1016/0017-9310(94)00241-M.

Yan, W. M., Lin, T.F., 1988, "Combined heat and mass transfer in laminar forced convection channel flows," Int. Comm. Heat Mass Transfer, 15, 333-343. http://dx.doi.org/10.1016/0735-1933(88)90034-6.

Zheng, G. S., Worek, W. M., 1996, "Method of heat and mass enhancement in film evaporation," Int J.Heat Mass transfer, 39, 97 108.

http://dx.doi.org/10.1016/S0017-9310(96)85009-5. 